\title{
ДЕПРИВАЦИЯ СОЦИАЛЬНОЙ ИНКЛЮЗИИ НАСЕЛЕНИЯ ЗРЕЛОГО ВОЗРАСТА КАК УГРОЗА СОЦИАЛЬНОЙ БЕЗОПАСНОСТИ ${ }^{1}$
}

О.Е. Ноянзина (https://orcid.org/0000-0002-1252-6021), С.Г. Максимова (https://orcid.org/0000-0002-4613-4966), Д.А. Омельченко (https://orcid.org/0000-0002-2839-5070)

Алтайский государственнылй университет, Барнаул, Россия, e-mail:noe@list.ru,svet-maximova@yandex.ru,daria.omelchenko@mail.ru

В целях изучения проявлений депривации социальной инклюзии и социальных настроений населения зрелого возраста в контексте необходимости обеспечения социальной безопасности и преодоления эксклюзии данной возрастной группы авторским коллективом реализовано исследование среди населения городов и сельских поселений Алтайского края в возрасте зрелости (женщины 40-54 лет и мужчины 40-59 лет, $\mathrm{n}=318$ ). В рамках статьи описан ряд показателей депривации социальной инклюзии населения зрелого возраста, сделаны предсказания в отношении депривации социального участия в связи с личностными характеристиками респондентов. Сделан вывод, что социальные ресурсы взрослого населения во многом связаны с взаимообусловленными характеристиками уровня материальной обеспеченности и статуса занятости. Более трети опрошенных сталкивались с депривацией своих прав в связи с личностными особенностями, которые имели дискриминирующее значение, причем самым часто проявляющимся фактором социальной эксклюзии является возраст. Приближение к «пенсионному» возрасту для большей части опрошенных, не обладающих существенными финансовыми гарантиями благополучия и стабильности, ведет к усилению социальной тревожности, ощущения небезопасности будущего, социальной незащищенности и депривации социального участия.

Ключевые слова: инклюзия, сочиальная безопасность, сочиальная эксклюзия, социальная адаптаџия, деприваџия, взрослое население, Алтайский край.

\footnotetext{
1 Публикация подготовлена в рамках выполнения гранта РФФИ № 19-011-00417 «Факторы и механизмы формирования доверия в системе сохранения социальной безопасности в приграничных регионах России» (2019-2021 гг.).
} 


\title{
DEPRIVATION OF SOCIAL INCLUSION OF ADULT POPULATION AS A THREAT FOR SOCIAL SECURITY
}

\author{
O.E. Noyanzina, S.G. Maximova, D.A. Omelchenko \\ Altai State University, Barnaul, Russia, \\ e-mail:noe@list.ru,svet-maximova@yandex.ru,daria.omelchenko@mail.ru
}

With the aim of study about indexes of deprivation of social inclusion and social moods of adult population authors realized survey among urban and rural adult population of the Altai region (women at the age of $40-54$, men at the age of $40-59, \mathrm{n}=318$ ). Paper describes a number of indexes of deprivation of social inclusion of adult population and makes predictions about deprivation of social participation because of persona characteristics of respondents. Concluded, that social resources of adult population mainly related with interdependent characteristics of the level of material provision and status of employment. More than a third of respondent suffered from deprivation of their rights because of personal peculiarities, having discriminated meaning, while the age was the most often revealed factor of social exclusion. Approaching retirement, respondents without considerable financial guarantees of well-being and stability tend to the strengthening of social anxiety, sense of unsafe future, social vulnerability and deprivation of social participation.

Keywords: inclusion, social security, social exclusion, social adaptation, deprivation, adult population, the Altai region.

\section{DOI 10.14258/ssi(2019)3-6364}

\section{Введение}

Состояние социальной безопасности определяется, во-первых, существующими угрозами общероссийского масштаба, в целом типичными для всех субъектов Российской Федерации, во-вторых, уникальной структурой угроз социальной безопасности конкретного региона, обусловленных его геополитическим и социально-экономическим положением, однако на отмеченные проблемы социальной безопасности налагает свой отпечаток экономический статус региона, особенности его географического расположения, разделяемые населением культурные традиции, иные специфичные микроуровневые характеристики (Максимова и др., 2012). Одной из таких характеристик могут стать проявления социальной инклюзии/эксклюзии населения регионального социума.

В свою очередь, подход к оценке социальной эксклюзии должен предполагать анализ микроданных применительно к институциональному и локальному контекстам, а также индивидуальным жизненным стратегиям и их динамике (Rigg $\&$ Sefton, 2004). На индивидуальном уровне эксклюзия может проявляться как постоянное или хроническое социальное смещение, бедность иди другие нематериальные «недостатки». Человек может находиться в процессе движения к большей 
или меньшей социальной интеграции по разным направлениям. В данном контексте некоторые авторы, например, ДеВайлд (DeWilde, 2003), применяли к изучению проблем социальной эксклюзии положения теории жизненных циклов и перспектив, основателем которой обычно считают Сибома Роунтри (Rowntree, 1901). Жизненные циклы, социальные пути и накопление жизненного опыта включены в динамичные траектории большой длительности; переход - это изменение состояния, вхождение или выход из какой-то роли; поворотные точки представляют собой существенное изменение в поведенческих траекториях. Теория жизненных циклов традиционно рассматривает то, как индивиды адаптируются к разным событиям, социально определяют переходы между разными позициями, как стадии жизни переходят от одной комбинации переходов к другой в различных областях жизни. Индивидуальные особенности рассматриваются в контексте независимых жизненных циклов семей и их стратегий с целью балансирования собственных нужд, использования и распределения ресурсов. Жизненные циклы действуют в качестве переходов к или от оплачиваемой работе, благополучию, семье/домохозяйству, здоровью/болезни. Примером применения этой теории может служить использование традиционного жизненного цикла американской перспективы в изучении динамики бедности в Британии (Rigg \& Sefton, 2004).

Исследования (Alcock et al., 2003; Gallie \& Paugam, 2000; Leisering \& Leibfried, 1999; Paugam, 1999; Saraceno, 2002; Sverko et al., 2006; Verner \& Alda, 2004) делают очевидным понимание социальной эксклюзии как процесса формирования множественных неравенств. Механизмы эксклюзии представляют собой «кумулятивное целое», которое включает индивидуальные и семейные ценности людей, живущих в схожих обстоятельствах, и некие устоявшиеся диспозиции. В отличие от него, «кумулятивное неравенство» происходит от проблем, которые возникают в процессе сравнения себя с окружающими, особенно при отсутствии семейной поддержки (Furstenberg, 2009). Схожим образом некоторые исследования доказывают, что чем длительнее состояние безработицы, тем хуже состояние здоровья безработного (Bartley \& Plewis, 2002), хотя очевидного доказательства последствий кумулятивного неравенства пока не существует.

Некоторые исследователи определяют социальную эксклюзию как нисходящую спираль кумулятивного неравенства. Например, Галли и Погэм отмечали, что «социальная эксклюзия имеет отношение к ситуации, в которой люди страдают от кумулятивного неравенства при маргинализации на рынке труда, бедности и социальной изоляции. Различные аспекты депривации постоянно усиливают друг друга, формируя нисходящую спираль, по которой движется индивид, не имеющий ни экономических, ни социальных ресурсов, необходимых для участия в делах общества или сохранения чувства социальной ценности» [Gallie \& Paugam, 2000: 370].

Несомненным достижением разнообразных исследований в области социальной эксклюзии является то, что некоторые проявления социальной изоляции не связаны с другими; это приводит к мысли о том, что процессы «накопления» неравенства - порочные круги, нисходящие спирали и т.п. - не так уж и часто случаются, как это может показаться. Некоторые авторы приходят к идее о том, что 
разрыв социальных отношений лишь частично изменяется в зависимости от форм материальной или экономической депривации [Barnes et al., 1969; Douglas, 1966), а коммуникабельность / социальная изоляция имеет свое собственное динамичное отличие от постоянной бедности и по этой причине не имеет очевидных различий как в группах множественно депривированного меньшинства, так и благополучного большинства (Whelan et al., 2002).

Итак, в формировании социальной эксклюзии большее значение имеют индивидуальные стратегии входа и выхода из этого состояния и ситуации, однако не следует забывать и о том, что социальная эксклюзия обусловливается в том числе и принадлежностью индивида к группе. Социальные границы или существование в обществе межгрупповых различий приводят к социальной эксклюзии определенных групп.

Научный интерес к изучению социальных границ эксклюзии существенно усилился в последние годы в ответ на растущую миграцию, мобильность капитала и трансформацию гендерной проблематики. Социальные границы между группами и людьми наиболее проницаемы, формальны, более заметны, комплексны и специфичны, чем все прочие различия, а принадлежность к группе «загоняет» индивида в определенные рамки. Оформление четких границ делает группу «особой», отличающейся от других, и ее члены разделяют эти особенности, проводят «черту», которая отделяет их от других (даже если в этом нет необходимости). Единство членов группы подкрепляется созданием групповой субкультуры, некого «культурного дуализма» (Alexander, 2001; Barth, 1969; Douglas, 1966; Elias \& Scotson, 1994; Wimmer \& Lamont, 2006), и одновременным выделением атрибутов, маркирующих отличия от других групп. В итоге чужие становятся «иными», «чужими», «неверными» и так далее, а свои — «святыми», внутри группы все четко и ясно, вне - нет. Далее устанавливаются вунтригрупповые правила, в том числе требования к «новичкам», конфигурации отношений между «новичками» и «старожилами». Как отмечает Норберт Элиас, единство старожилов группы, семейственность, информированность и организация дают им власть стигматизации и исключения новичков. Вместе с тем доминирующие в обществе группы не могут существовать без социальных контактов вне ее, поэтому восприятие аутсайдеров как маргиналов и чужаков создает постоянную напряженность в межгрупповых отношениях.

Виммер и Ламон (Wimmer \& Lamont, 2006) в своих работах уделяли внимание генезису и изменению социальных границ через механизмы вовлечения акторов в работу по «строительству» социальных границ. Они доказали, что культурные, символические и моральные причины имеют реальное влияние на социальные взаимодействия и доступ к групповым ресурсам. В ситуации усиливающихся межгрупповых взаимодействий границы могут принимать разные формы, они могут активироваться, социально закрываться от аутсайдеров. Так, Фрэнк Паркин (1979) доказывал, что исключенные группы могут сами вовлекаться в реактивные формы социальной закрытости, что он назвал «узурпацией», приданием ценности собственной группе и исключенности большинства (Parkin, 1979). И в таком процессе «двойного закрытия» границы группы только укрепляются, что придает группе чув- 
ство солидарности, организованности и ресурсы, необходимые для включенности. С другой стороны, границы могут стать более или менее открытыми, позволяя аутсайдерам проникать внутрь группы. Пересечение границы группы сопряжено с изменением идентичности индивида и сохранности самих границ.

Вместе с тем отметим важность учета групповых особенностей при изучении социальной эксклюзии. Слишком часто исследования в данной области фокусируются на жертвах эксклюзии, характеристиках и событиях их жизни. Это не позволяет вскрыть отношения между вовлеченными в процесс эксклюзии, роли, которые играют в этом процессе как сами исключаемые, так и те, кто их исключает. Индивидуальные микроуровневые данные не могут охватить дискриминацию и другие «исключающие» взаимоотношения между инсайдерами и аутсайдерами, поэтому следует обращать внимание на групповые отношения и коллективные процессы. Например, религиозная, этническая, расовая или гендерная эксклюзия может быть «закодирована» в обезличенных законах, препятствующих социальному участию.

Целью данной статьи является изучение проявлений депривации социальной инклюзии и социальных настроений населения зрелого возраста в контексте необходимости обеспечения социальной безопасности и преодоления эксклюзии данной возрастной группы.

\section{Методы}

В исследовании особенностей проявлений депривации социальной инклюзии и социальных настроений населения (2017) приняли участие жители городов и сельских поселений Алтайского края в возрасте зрелости (женщины 40-54 лет и мужчины 40-59 лет, $\mathrm{n}=318$ ), доля опрошенных женщин несколько превысила долю мужчин (51,3\% и 48,7\%).

Принципы планирования выборки исследования учитывали два аспекта: с одной стороны, репрезентативность для регионов в целом, а с другой - достаточно компактное размещение по территории. «С учетом этих обстоятельств использована схема районированной (стратифицированной) пропорциональной выборки в сочетании с серийным отбором (многоступенчатая выборка с использованием квотного отбора). Поскольку такая выборка относится к „территориальным,“, структура которых определяется в соответствии со структурой занятости, планирование выборки предусматривало отражение корреляции условий обитания с социальными характеристиками респондентов» (Максимова и др., 2014). Используемая выборка репрезентативна по параметрам пола, возраста и типу населенного пункта.

С точки зрения социально-экономического развития Алтайский край характеризуется рядом особенностей качества и уровня жизни. В крае присутствуют объективные условия для формирования социальной эксклюзии населения не только и даже не столько пожилой части населения, но ее трудоспособной части: высоки риски материальной депривации населения всех возрастных групп, что существенно ограничивает возможности удовлетворения потребностей и интересов проживающего населения. Регион не относится к числу регионов-лидеров, доноров как окружной, так и российской экономики, показатели, связанные с качеством жизни, 
имеют тенденцию в большинстве случаев к ухудшению. Вместе с тем такая ситуация не является уникальной, а отражает кризисные явления, свойственные экономике всей страны в целом.

Методы сбора информации - формализованное интервью по месту жительства населения. Количественные данные обработаны с использованием статистического пакета обработки данных SPSS 23.0. Для обоснования логики статистического вывода применены соответствующие природе данных (номинативной или количественной) и характеру распределений статистические методы (дисперсионный и факторный анализ, построение таблиц сопряженности с оценкой статистической значимости различий относительных показателей).

В рамках статьи использованы следующие показатели депривации социальной инклюзии и социальных настроений населения зрелого возраста в контексте необходимости обеспечения социальной безопасности и преодоления эксклюзии данной возрастной группы: оценки степени адаптированности к современным условиям жизни, оценка удовлетворенности собственной жизнью, оценка наполненности событиями будней, удовлетворенность взаимодействием с окружением, депривация прав в связи с личностными особенностями, социальные настроения, актуальные потребности, которые не могут быть удовлетворены в силу отсутствия возможностей, ресурсов.

\section{Результаты и обсуждение}

Не адаптироваться, не приспособиться к динамично меняющимся жизненным реалиям - значит, не уметь в полной мере пользоваться доступными социальными и иными ресурсами, вовремя перестраивать свое отношение, поведение, вырабатывать адекватные адаптивные стратегии. Только четверть участников исследования считают себя полностью приспособившимися к современным условиям жизни, доминирующей оценкой выступают мнения о частичной приспособленности к жизни («скорее приспособился» - 43,9\%), четверть опрошенных в чем-то приспособились, а в чем-то - нет, 5,4\% полагают, что они скорее не приспособлены, а 0,4\% уверены, что они совершенно не приспособлены к жизни в современном мире. С помощью классификации, проведенной на основе применения метода дерева решений, можно сделать выводы о зависимости в оценках степени адаптированности к современной жизни от характеристик уровня материальной обеспеченности и статуса занятости.

Первый этап классификации продемонстрировал наличие связи между двумя оценками - уровня приспособленности к современным условиям и уровня материального достатка. Ощущение себя обеспеченным в 44,3\% случаев приведет к пониманию большей приспособленности к современной жизни, чем ощущение себя бедным, очень бедным и богатым (31,2\% скорее приспособившихся). Более размытые оценки степени адаптации к изменениям наблюдаются в группе среднеобеспеченных, где на втором этапе классификации доказана зависимость от статуса занятости: полностью приспособились среднеобеспеченные руководители и работающие пенсионеры (34\%), скорее приспособились оценивающие себя среднеобеспеченны- 
ми наемные работники (48,2\%), среднеобеспеченные незанятые вероятнее попадут в группу скорее приспособившихся (36,3\%).

Большинство опрошенных скорее приспособились к современным условиям, на первом шаге классификации выделены две группы в зависимости от самооценки материального статуса, достоверно скорее приспособившиеся к жизни - это достаточно обеспеченные жители, у которых есть практически все, что необходимо для жизни (44,3\%), а также достоверно «ужившиеся» со своим положением бедные, очень бедные и очень богатые опрошенные (31,2\%). Более зависимыми оказались оценки респондентов со средним уровнем достатка: достоверно чаще полностью приспособленными будут имеющие статус руководителя (40,2\%), а скорее приспособившимися - большая часть наемных работников $(48,2 \%)$ и незанятых $(36,3 \%)$.

Таким образом, принадлежность к тому или иному полюсу шкалы «бедность - богатство» скорее будет способствовать адаптации к условиям жизни, чем средний уровень достатка, где достоверно по-разному ощущают свою приспособленность руководители и занимающие подчиненное положение: вторые с большей долей вероятности будут ощущать себя скорее, а не полностью приспособленными.

Несмотря на обилие сложностей, не всегда благоприятные социально-экономические условия жизни и другие проблемы, абсолютное большинство опрошенных жителей региона частично или полностью удовлетворены своей жизнью $(85,8 \%)$ : $15,5 \%$ удовлетворены полностью, $40,4 \%$ - скорее удовлетворены и $29,9 \%$ - в чемто удовлетворены, в чем-то - нет. Небольшая доля участников исследования считают, что их скорее не удовлетворяет собственная жизнь, а 2,2\% - совершенно не довольны жизнью. С целью предсказания вероятности попасть в ту или иную категорию удовлетворенных жизнью мы использовали метод построения деревьев решений, согласно которому удовлетворенность опять-таки достоверно предопределена материальным статусом. Обеспеченная и богатая часть населения достоверно будет скорее удовлетворена собственной жизнью (45,7\%), а вот ощущающие себя бедными и очень бедными, нищими достоверно менее довольны жизнью, которая их в чем-то удовлетворяет, а в чем-то нет $(33,8 \%)$. В отношении группы обеспеченных на среднем уровне граждан Алтайского края на втором шаге классификации выявлена достоверная зависимость от уровня образования опрошенных: принадлежность к группе с начальным профессиональным образованием достоверно будет снижать ощущение общей удовлетворенности, смещая оценки к негативному полюсу: в чемто удовлетворены, а в чем-то - нет 43,0\% этой группы, тогда как в группе с отличающимся от начального профессионального образованием опрошенные достоверно чаще скорее удовлетворены жизнью $(43,8 \%)$.

Ощущение себя в центре событий, наполненность и насыщенность ими повседневности, нехватка свободного времени формируют ощущение собственной значимости, востребованности окружающими не только с позиций личностных качеств, но и сформированных профессиональных компетенций, т.е. ощущение полной включенности в социальные связи и отношения. Более трети опрошенных (36,7\%) ощущают нехватку времени, поскольку у них очень много дел, примерно столько же полагают, что у них хватает дел, но по обыкновению никуда не торопят- 
ся (31\%), пятая часть (19,8\%) имеет достаточное количество занятий, чтобы вообще не думать о свободном времени. Лишь небольшая часть респондентов имеют свободное время: достаточно много - 8,8\%, много свободного времени, потому что мало дел - 2,9\%, а у $1 \%$ опрошенных вообе нет никаких дел. Таким образом, чуть более 10 процентов опрошенных ощущают незанятость будней в силу незанятости, отсутствия занятий, каких-либо дел, соответственно, вероятно, лишены осознания собственной востребованности и включенности в происходящие процессы и особенно в управление ими.

Рассмотрим, какие группы опрошенных достоверно чаще попадают в категорию исключенных из таких процессов. Наполненность повседневной жизни женщин достоверно выше, чем у мужчин: только 6,8\% женщин имеют достаточно свободного времени (10,4\% мужчин), имеют мало дел 2,6\% женщин и $3 \%$ мужчин, вообще нет дел только у $0,2 \%$ женщин и $1,7 \%$ мужчин. Конечно, наличие свободного времени достоверно зависит и от статуса занятости: более свободными и незанятыми являются неработающие пенсионеры и неработающие. Так, обладают свободным временем (суммарно по трем позициям «достаточно много времени», «мало дел и много времени», «вообще нет дел») 5,9\% руководителей, 9,6\% наемных работников, 16,3\% неработающих пенсионеров и 31,5\% незанятых.

Также много свободного времени у имеющих неоконченное высшее образование (суммарно $31 \%$ ) и среднее общее $(24,1 \%)$, более насыщены делами будни у тех опрошенных, которые имеют среднее профессиональное $(13,3 \%)$, начальное профессиональное 8,9\% или высшее 12,1\% образование. Имеющие семью чаще ощущают нехватку времени, а не состоящие в браке по разным причинам - имеют его в достатке: никогда в браке не состоявшие - суммарно 25,9\%, разведенные суммарно $20 \%$, вдовые - $17 \%$, сожительствующие - $12,9 \%$, состоящие в браке только в 9,5\% случаев ощущают наличие свободного времени и отсутствие дел. Достоверно заполняет свободное время и религия: ощущают свободу от дел суммарно $9 \%$ считающих себя последователями определенной религии, $12,9 \%$ - верующих в бога по-своему, 16,3\% - неверующих и 17\% атеистов.

Отметим и наличие возрастных зависимостей: чем моложе опрошенный, тем менее заполнены его дни и тем больше у него разнообразных занятий: ощущают свободу действий и свободу времени суммарно 18,9\% опрошенных в возрасте от 40 до 44 лет; 10,6\% — в возрасте от 45 до 49 лет, 10,2\% — от 50 до 54 лет и 7,4\% в возрасте 55-59 лет.

Таким образом, можно предположить, что незанятые, не имеющие детей и семьи опрошенные с большей вероятностью подвержены риску исключения из социальных связей. Скорее всего, «выпадание» именно членов семьи и коллег из круга общения в силу отсутствия, занятости или каких-то еще других причин не приводит к «замещению» их участия, поддержки, т.е., вероятнее всего, их место в социальной жизни опрошенного остается незаполненным.

Но приносит ли взаимодействие с окружающими удовлетворенность участникам исследования, в том числе насколько позитивно относятся респонденты к самим себе и своему здоровью? Мы просили жителей Алтайского края определить, насколь- 
ко они удовлетворены взаимоотношениями с близкими и самим собой. Данная оценка проведена по пятибалльной шкале, где 1 балл обозначал «совершенно не удовлетворен», 5 - «абсолютно удовлетворен». Для удобства восприятия мы суммировали минимальные и максимальные оценки, в соответствии с которым опрошенные разделились на три группы - удовлетворенных взаимоотношениями с окружающими и собой, не удовлетворенных и в чем-то удовлетворенных, в чем-то - нет.

С позиций изучения проявлений социальной эксклюзии рассмотрим оценки в группе опрошенных, которые не удовлетворены имеющимися взаимоотношениями. Так, чаще всего неудовлетворенность возникает по поводу собственного здоровья $(14,2 \%)$, на втором месте после неудовлетворительного состояния здоровья взаимоотношения с внуками (13,9\% выборов опрошенных), далее, с некоторым отрывом - неудовлетворенность самим собой - 9,7\%, супружескими взаимоотношениями $(8,7 \%)$, отношениями с родителями $(7,6 \%)$, менее всего приносят разочарование поддержка семьи $(6,3 \%)$ и взаимоотношения с детьми $(4,7 \%)$.

Анализ таблиц перекрестных распределений позволил выявить следующие значимые зависимости степени неудовлетворенности собой и близкими: поддержкой семьи достоверно чаще не удовлетворены безработные (в совокупности 17,2\% незанятых, 7,9\% - неработающих пенсионеров, 5,3\% - наемных работников и $6,9 \%$ - руководителей), а также бедные $(19,4 \%)$ и исповедующие конкретную религию $(5 \%)$ и верующие по-своему $(7,4 \%)$; взаимоотношениями с родителями неработающие пенсионеры $(27,5 \%)$ и незанятые $(13,9 \%)$, считающие себя очень бедными (25\%) и просто бедными $(21,1 \%)$; взаимоотношениями с детьми и внуками - также незанятые (10\% и 42,9\% соответственно), неработающие пенсионеры ( $10 \%$ и $28,5 \%$ соответственно) и считающие себя бедными (13\% не удовлетворены общением с детьми, 24,7\% - с внуками) и очень бедными (20\% не удовлетворены общением с внуками). Отметим, что 16,6\% атеистов не довольны взаимоотношениями с детьми; супружескими отношениями - женщины достоверно чаще не получают удовлетворения от супружеских взаимоотношений (совсем и скорее не удовлетворены $12,6 \%$ женщин и $8,1 \%$ мужчин) и исключительно незанятая часть опрошенных $(19,4 \%)$, очень бедные $(20 \%)$ и бедные $(20,9 \%)$, опрошенные с низким образовательным уровнем (16\% с общим средним образованием) и старшей возрастной группы — от 55 до 59 лет (17,8\%); своим здоровьем - незанятые $(19,4 \%)$ и неработающие пенсионеры (15\%), очень бедные $(20 \%)$ и бедные $(30,1 \%)$; самим собой - преимущественно незанятые $(20,3 \%)$ и неработающие пенсионеры $(17,7 \%)$, подавляющее большинство очень бедных (80\%) и бедных (24\%).

Таким образом, мы получили еще одно подтверждение о существенной связи таких явлений, как бедность и эксклюзия. Бедность, низкий социальный и образовательный багаж не только исключают индивида из системы социальных связей, но и продуцируют тотальную неудовлетворенность в ближнем окружении, его поддержке.

В дальнейшем мы выясняли, сталкивались ли опрошенные с фактами нарушения, депривации своих прав в связи с личностными особенностями, которые имели дискриминирующее значение и не позволяли получить ту или иную рабо- 
ту, должность, а также продвигаться по карьерной лестнице. Факты депривации, их частота оценивались также по пятибалльной шкале от 1 - «никогда» до 5 «очень часто». На рисунке представлено распределение суммарных оценок «часто» и «очень часто» по основаниям депривации прав опрошенных (значение в три балла на шкале означало «не уверен», поэтому при суммировании не учитывалось). Итак, в Алтайском крае самым часто проявляющимся фактором социальной эксклюзии является возраст $(18,1 \%)$, далее отмечена (11,1\% выборов) депривация из-за материального положения, гендерная принадлежность опрошенных - 9,9\%, мировоззрение (убеждения и взгляды) - 7,8\%, семейное положение $(7,3 \%)$, и, на последнем месте по доле проявлений — фактор этничности (5,8\%).

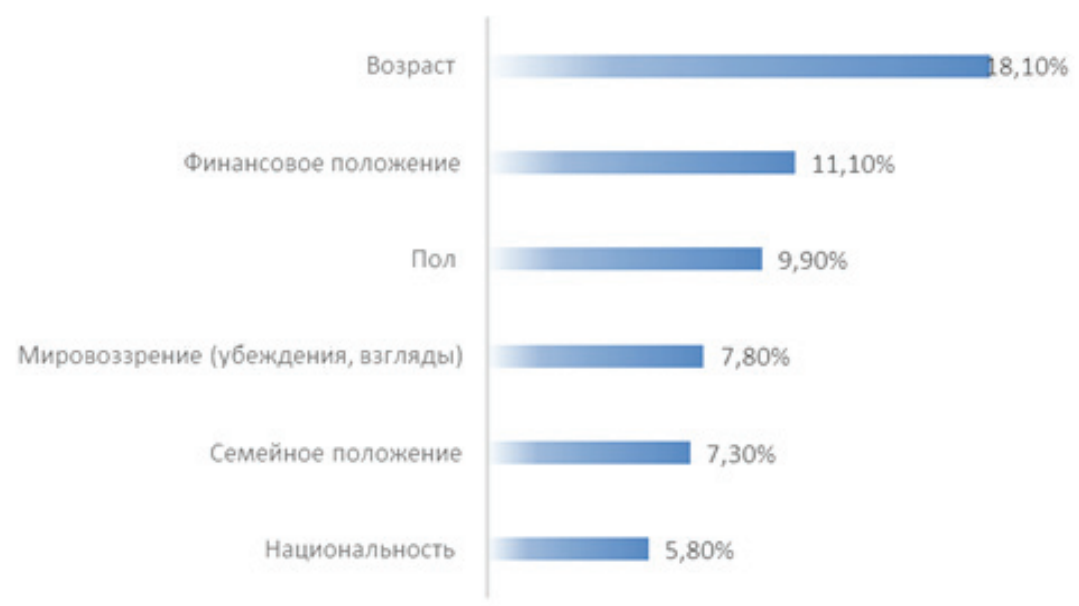

Депривация прав опрошенных в связи с личностными особенностями, \%

На основе классификации по методу деревьев решений получены предсказания вероятности депривации по разным основаниям.

Итак, дискриминация по возрасту достоверно зависит от материального положения опрошенных, и немногим более защищенными от ее проявлений являются богатые и очень богатые опрошенные (67,7\% никогда не сталкивались с дискриминацией по возрасту и $21,5 \%$ - очень редко).

Характеристикой, значимо связанной с депривацией гендерной принадлежности, выступила занятость опрошенного, а именно незанятые достоверно чаще подвергаются дискриминации по полу в рассматриваемых регионах. Отсутствие занятости также чаще приводит к дискриминации по критерию принадлежности к этнической группе, мировоззрения и убеждений, а также семейного положения.

Выявлена достоверная зависимость между дискриминацией из-за финансового положения и семейным положением и статусом занятости. По итогам первого этапа классификации достоверно более подверженными риску дискриминации изза финансового положения оказались вдовые опрошенные (17,5\%), на втором этапе 
отражена большая вероятность дискриминации по рассматриваемому основанию в группе незанятых опрошенных всех семейных статусов, кроме вдовых.

Участники исследования чаще всего спокойно, без особых надежд и иллюзий смотрят в будущее (44,4\% выборов опрошенных), более трети - с надеждой и оптимизмом $(37,4 \%)$, а довольно существенная часть опрошенных - с тревогой и неуверенностью $(15,1 \%)$ и страхом и отчаяньем $(2,4 \%)$. Но по результатам распределения ожиданий опрошенных сложно сделать вывод, связаны ли тревожные ожидания с предстоящим выходом на пенсию либо обусловлены какими-либо иными факторами. Для выявления связи между оценкой устремлений в будущее и характеристиками опрошенных обратимся к результатам классификации. Единственной в данном случае достоверной зависимостью явилось предсказание тональности социальных настроений в связи с оценками материального положения. Так, богатые и очень богатые респонденты смотрят в будущее преимущественно в позитивном ключе $(58,3 \%)$ и спокойно, без особых иллюзий $(33,9 \%)$, настроения бедных и очень бедных достоверно смещаются в сторону негатива и нарастания тревожности $(25,3 \%)$ и даже страха $(8,4 \%)$. В группе опрошенных, считающих себя обеспеченными на среднем уровне, несмотря на то что большинство значимо чаще смотрят на свое будущее спокойно, без особых надежд (47,8\%), довольно распространены тревожные опасения (16\%) и даже страхи $(2 \%)$.

Насколько удовлетворены иные потребности и интересы современного населения, находящегося в активном возрасте? Оценка степени удовлетворенности потребностей и интересов взрослого населения проводилась с использованием следующих маркеров: «не испытываю потребности», «не могу себе позволить», «в небольшой степени удовлетворен» и «в значительной степени удовлетворен». С позиций задач исследования рассмотрим потребности и интересы опрошенных, удовлетворить которые они не могут в силу ограниченных возможностей.

Итак, самые проблемные сферы, решение которых не под силу опрошенным, - это: невозможность изменить материальный уровень жизни (76,3\% выборов опрошенных), количество и качество одежды и обуви $(74,5 \%)$, количество и качество продуктов питания (71,8\%), получить медицинское лечение $(69,8 \%)$, увеличить количество и качество лекарственных средств (67,2\%), посещать культурные центры $(59,9 \%)$, расширить круг общения (55\%), трудоустроиться (54\%), заниматься хобби (53\%), передавать накопленный опыт (52,5\%) и улучшить жилищные условия (48,5\%). Таким образом, более чем каждый второй депривирован из-за неудовлетворения как минимум одной важной для полноценного жизнеосуществления потребности.

Сетуют на отсутствие возможности: улучшить количество и качество продуктов питания - достоверно чаще женщины $(12,8 \%)$, незанятые $(10,8 \%)$, бедные $(28,8 \%)$; лучше одеваться и обуваться - достоверно чаще женщины $(15,2 \%)$, бедные (33,3\%); посещать музеи, выставки, концерты, библиотеки - достоверно чаще мужчины (19,1\%), неработающие пенсионеры (17,3\%) и незанятые $(21,9 \%)$, бедные $(33,3 \%)$ и очень бедные $(29,2 \%)$; улучшить материальное положение - достоверно чаще неработающие пенсионеры $(34,6 \%)$ и незанятые $(33,8 \%)$, бедные $(52,1 \%)$, опрошенные с низким образовательным статусом $(26,8 \%$ - со средним уровнем 
образования, 28,6\% - с неполным высшим образованием); получить лечение достоверно чаще неработающие пенсионеры (25\%) и незанятые $(24,7 \%)$, бедные (31,9\%); трудоустроиться - достоверно чаще незанятые $(33,8 \%)$, бедные $(26 \%)$; улучшить жилье - достоверно чаще незанятые $(21,6 \%)$, бедные $(17,8 \%)$, опрошенные с низким образовательным статусом (11,6\% со средним полным образованием, $12,5 \%$ - с начальным профессиональным уровнем образования), представители всех групп опрошенных по отношению к религии за исключением исповедующих конкретную религию; расширить круг общения - достоверно чаще неработающие пенсионеры $(15,4 \%)$ и незанятые $(15,3 \%)$, бедные $(24,7 \%)$ и очень бедные $(16,7 \%)$; транслировать опыт - достоверно чаще неработающие пенсионеры $(17,3 \%)$ и очень бедные $(33,3 \%)$; заняться хобби - как ни странно, достоверно незанятые $(28,3 \%)$, очень бедные $(33,3 \%)$ и бедные $(31,9)$.

\section{Выводы}

На основе описания данных, представленных в отношении степени адаптированности опрошенных к условиям жизни в Алтайском крае, депривации основных потребностей, формирующих качество и дающих ощущение достойного уровня жизни и безопасности, приведем основные выводы.

Мы живем в обществе, которое динамично меняется, эти изменения зачастую стремительны и вызывают радикальные трансформации в жизни современного человека, системе и структуре социальных отношений, экономике и организации рынка труда, общественно-политических условиях и т.д. Несмотря на то что о проблемах адаптации человечества к растущим темпам социального и технического прогресса Олвин Тоффлер впервые написал в своей статье «Шок будущего» еще в 1965 г., до сих пор не существует эффективного механизма формирования адаптивного поведения разных групп населения в меняющемся обществе. Только четверть участников исследования считают себя полностью приспособившимся к современным условиям жизни, доминирующей оценкой выступают мнения о частичной приспособленности к жизни («скорее приспособился»), около 6\% уверены в том, что они так и не смогли приспособиться к современной жизни.

Как ни банально, адаптационные ресурсы взрослого населения во многом связаны с взаимообусловленными характеристиками уровня материальной обеспеченности и статуса занятости. Смогли успешно приспособиться к жизни преимущественно достаточно обеспеченные жители, у которых есть практически все, что необходимо для жизни, а также достоверно «ужившиеся» со своим положением бедные, очень бедные и очень богатые опрошенные. Принадлежность к тому или иному полюсу шкалы «бедность - богатство» скорее будет способствовать адаптации к условиям жизни, чем средний уровень достатка, где достоверно по-разному ощущают свою приспособленность руководители и занимающие подчиненное положение: вторые с большей долей вероятности будут ощущать себя скорее, а не полностью приспособленными. Общая удовлетворенность жизнью опять-таки достоверно предопределена материальным статусом.

Ощущение себя в центре событий, наполненность и насыщенность ими по- 
вседневности, нехватка свободного времени формируют ощущение собственной значимости, востребованности окружающими не только с позиций личностных качеств, но и сформированных профессиональных компетенций, т.е. ощущение полной включенности в социальные связи и отношения. Незанятые, не имеющие детей и семьи опрошенные с большей вероятностью подвержены риску исключения из социальных связей, «выпадание» членов семьи и коллег из круга общения в силу отсутствия занятости или каких-то других причин не приводит к «замещению» их участия, поддержки.

Более трети опрошенных сталкивались с депривацией своих прав в связи с личностными особенностями, которые имели дискриминирующее значение и не позволяли получить ту или иную работу, должность, а также продвигаться по карьерной лестнице: самым часто проявляющимся фактором социальной эксклюзии является возраст, далее отмечена депривация из-за материального положения, гендерной принадлежности, мировоззрения (убеждения и взгляды) и семейного положения - и на последнем месте по доле проявлений фактор этничности. Обратим внимание, что дискриминация по возрасту достоверно зависит от материального положения опрошенных, и от ее проявлений немногим более защищенными являются богатые и очень богатые опрошенные. Характеристикой, значимо связанной с деприваций гендерной принадлежности, выступила занятость опрошенного, а именно незанятые достоверно чаще подвергаются дискриминации по полу.

Существенная часть опрошенных смотрят в свое будущее с тревогой и неуверенностью и даже страхом и отчаяньем. Единственной в данном случае достоверной зависимостью явилось предсказание тональности социальных настроений в связи с оценками материального положения: богатые и очень богатые респонденты смотрят в будущее преимущественно в позитивном ключе и спокойно, без особых иллюзий, настроения бедных и очень бедных достоверно смещаются в сторону негатива и нарастания тревожности и даже страха, которые в совокупности переживают почти четверть бедных и очень бедных жителей края. Более чем каждый второй участник исследования депривирован из-за неудовлетворения как минимум одной важной для полноценного жизнеосуществления потребности.

Таким образом, приближение к «пенсионному» возрасту для большей части опрошенных, не обладающих существенными финансовыми гарантиями благополучия и стабильности, ведет к усилению социальной тревожности, ощущения небезопасности будущего, социальной незащищенности и депривации социального участия.

\section{БИБЛИОГРАФИЧЕСКИЙ СПИСОК}

Максимова С.Г., Гончарова Н.П., Ноянзина О.Е., Омельченко Д.А., Авдеева Г.С. Методика формирования региональных выборок в социально-экономическом исследовании рисков и безопасности населения приграничных территорий. Вестник АГАУ, 2014, No. 8, 153-159.

Максимова С.Г., Ноянзина О.Е., Гончарова Н.П., Омельченко Д.А., Авдеева Г.С. Модели конструирования новой геронтологической реальности и адаптивные страте- 
гии населения России. Барнаул: Азбука, 2012.

Alcock P., Beatty C., Fothergill S., Macmillan R., Yeandle, S. Work to Welfare: How Men Become Detached from the Labour Market. Cambridge: Cambridge University Press, 2003.

Alexander J. Theorizing the Modes of Incorporation: Assimilation, Hyphenation, and Multiculturalism as Varieties of Civil Participation. Sociological Theory, 2001, 19(3), 237-249.

Barnes M., Heady C., Middleton S., Millar J., Papadopoulos F., Room G., Tsakloglou P. Poverty and Social Exclusion in Europe. Cheltenham: Edward Elgar, 2002.

Barth F. Ethnic Groups and Boundaries: The social organization of culture difference. London: Allen \& Unwin, 1969.

Bartley M., Plewis I. Accumulated labour market disadvantage and limiting long-term illness: Data from the 1971-1991 Office for National Statistics' Longitudinal Study. International Journal of Epidemiology, 2002, No. 31, 336-341.

DeWilde, C. A life-course perspective on social exclusion and poverty. British Journal of Sociology, 2003, 54(1), 109-128.

Douglas M. Purity and Danger: An Analysis of Concepts of Pollution and Taboo. London: Routledge \& Kegan Paul, 1966.

Elias N. Scotso J.L. The Established and the Outsiders: A Sociological Enquiry into Community Problems, 2nd ed. London: Sage, 1994.

Furstenberg F., Cook D., Eccles J., Elder G. Sameroff A. Managing to Make it: Urban Families and Adolescent Success. Chicago: University of Chicago Press, 1999.

Gallie D., Paugam S. (Eds.). Welfare Regimes and the Experience of Unemployment in Europe. Oxford: Oxford University Press, 2000.

Leisering L., Leibfried S. Time and Poverty in Western Welfare States: United Germany in Perspective. Cambridge: Cambridge University Press, 1999.

Parkin F. Marxism and Class Theory: A Bourgeois Critique. New York: Columbia University Press, 1979.

Paugam S. Weakening and breaking of social ties: Analysis of explanatory factors. In: Avramov D. (Ed.). Coping with Homelessness: Issues to be Tackled and Best Practice in Europe. Ashgate: Aldershot, 1999. Pp. 29-51.

Rigg J., Sefton T. Income dynamics and the life cycle. LSE CASE Papers. London: Centre for Analysis of Social Exclusion, 2004.

Rowntree B.S. Poverty: A Study of Town Life. London and New York: Macmillan, 1901.

Saraceno C. (Ed.) Social Assistance Dynamics in Europe: National and Local Poverty Regimes. Bristol: Policy Press, 2002.

Sverko B., Galic Z., Sersic D. Unemployment and social exclusion: A longitudinal study. Revija za Socijalnu Politiku, 2006, 13(1), 1-14.

Verner D., Alda E. Youth at risk, social exclusion, and intergenerational poverty dynamics: a new survey instrument with application to Brazil. Policy Research Working Paper Series, 
2004, No. 3296.

Whelan C., Layte R., Maitre B. Multiple deprivation and persistent poverty in the European Union. Journal of European Social Policy, 2002, 12(2), 91-105.

Wimmer A., Lamont M. Toward a sociology of boundary making. Paper presented to the American Sociological Association, Montreal, 2006, August, 11.

\section{REFERENCES}

Maksimova, S.G., Goncharova, N.P., Noyanzina, O.E., Omelchenko, \& D.A., Avdeeva, G.S. (2014). Metodika formirovaniya regional'nyh vyborok v social'no-ekonomicheskom issledovanii riskov i bezopasnosti naseleniya prigranichnyh territorij [Method of formation of regional samplings in social-economy research about risks and security of population in boundary territories]. Vestnik $A G A U$, no 8, 153-159.

Maksimova, S.G., Noyanzina, O.E., Goncharova, N.P., Omelchenko, D.A., \& Avdeeva, G.S. (2012). Modeli konstruirovaniya novoj gerontologicheskoj real'nosti i adaptivnye strategii naseleniya Rossii [Models of construction of a new gerontology reality and adaptive strategies of Russian population]. Barnaul : Azbuka.

Alcock, P., Beatty, C., Fothergill, S., Macmillan, R., \& Yeandle, S. (2003). Work to Welfare: How Men Become Detached from the Labour Market. Cambridge: Cambridge University Press.

Alexander, J. (2001). Theorizing the Modes of Incorporation: Assimilation, Hyphenation, and Multiculturalism as Varieties of Civil Participation. Sociological Theory, no 19(3), 237-249.

Barnes, M., Heady, C., Middleton, S., Millar, J., Papadopoulos, F., Room, G., \& Tsakloglou, P. (2002). Poverty and Social Exclusion in Europe. Cheltenham: Edward Elgar.

Barth, F. (1969). Ethnic Groups and Boundaries: The social organization of culture difference. London: Allen \& Unwin.

Bartley, M., \& Plewis, I. (2002). Accumulated labour market disadvantage and limiting long-term illness: Data from the 1971-1991 Office for National Statistics' Longitudinal Study. International Journal of Epidemiology, no 31, 336-341.

DeWilde, C. (2003). A life-course perspective on social exclusion and poverty. British Journal of Sociology, 54(1), 109-128.

Douglas, M. (1966). Purity and Danger: An Analysis of Concepts of Pollution and Taboo. London: Routledge \& Kegan Paul.

Elias, N., \& Scotson, J.L. (1994). The Established and the Outsiders: A Sociological Enquiry into Community Problems, 2nd ed. London: Sage.

Furstenberg, F., Cook, D. Eccles, J., Elder, G., \& Sameroff, A. (1999). Managing to Make it: Urban Families and Adolescent Success. Chicago: University of Chicago Press.

Gallie, D., \& Paugam, S. (Eds.) (2000). Welfare Regimes and the Experience of Unemployment in Europe. Oxford: Oxford University Press.

Leisering, L., \& Leibfried, S. (1999). Time and Poverty in Western Welfare States: United 
Germany in Perspective. Cambridge: Cambridge University Press.

Parkin, F. (1979). Marxism and Class Theory: A Bourgeois Critique. New York: Columbia University Press.

Paugam, S. (1999) Weakening and breaking of social ties: Analysis of explanatory factors. In Avramov, D. (Ed.), Coping with Homelessness: Issues to be Tackled and Best Practice in Europe (pp. 29-51). Ashgate: Aldershot.

Rigg, J., \& Sefton, T. (2004). Income dynamics and the life cycle. LSE CASE Papers. London: Centre for Analysis of Social Exclusion.

Rowntree, B.S. (1901). Poverty: A Study of Town Life. London and New York: Macmillan.

Saraceno, C. (Ed.) (2002). Social Assistance Dynamics in Europe: National and Local Poverty Regimes. Bristol: Policy Press.

Sverko, B., Galic, Z., \& Sersic, D. (2006). Unemployment and social exclusion: A longitudinal study. Revija za Socijalnu Politiku, 13(1), 1-14.

Verner, D., \& Alda, E. (2004). Youth at risk, social exclusion, and intergenerational poverty dynamics: a new survey instrument with application to Brazil. Policy Research Working Paper Series, no 3296.

Whelan, C., Layte, R., \& Maitre, B. (2002). Multiple deprivation and persistent poverty in the European Union. Journal of European Social Policy, 12(2), 91-105.

Wimmer, A., \& Lamont, M. (2006). Toward a sociology of boundary making. Paper presented to the American Sociological Association, Montreal, August, 11. 